\title{
Lait Nocard to rBCG - Over 100 Years of Experience with BCG Vaccine
}

\author{
*Mathan Periasamy, Manjula Datta, M. Kannapiran \\ Department of Biotechnology, Sree Sastha Institute of Engineering and Technology, Chennai-123, India \\ Department of Epidemiology (Rtd), the Tamilnadu Dr. M.G.R. Medical University, Chennai-32, India \\ Department of Biochemistry (Rtd), National Institute for Research in Tuberculosis, ICMR, Chennai-31, India. \\ Corresponding Author: Mathan Periasamy
}

\section{Introduction}

Tuberculosis (TB) continues to be a major worldwide health problem and is the leading killer of youth and adults in developing countries, being responsible for more deaths than any other single infectious organism [1]. 5-15\% of the people infected with M. tuberculosis (estimated 2-3 billion) will develop TB disease during their lifetime [1]. Bacillus Calmette-Guerin (BCG), an attenuated strain of Mycobacterium bovis is the only vaccine currently available against TB. This is the world's most widely used vaccine and being directed against the world's leading cause of infectious disease mortality, BCG is the most controversial vaccine in current use [2]. The efficacy of BCG vaccine in the prevention of tuberculosis has shown considerable variation in different populations and trials [3]. Results from those trials showed $0-80 \%$ of protection and particularly those from South India have shown no protection. The on-going research on new TB vaccines may take several years as it involves earlier safety testing and efficacy field trials. This review article discusses about the earlier historical attempts to the recent advancements in $\mathrm{TB}$ vaccines with special reference to modern recombinant vaccines.

\section{Earlier History behind BCG}

In 1896, Leon Charles Albert Calmette (1863 - 1933), a French physician was appointed as the director of the Pasteur Institute of Lille, France, and the main public problem which he had to contend with was tuberculosis. Meantime, Jean Marie Camille Guerin (1872 - 1961), a French veterinary surgeon was appointed to assist Calmette in 1897 and both have decided to proceed with research on tuberculosis vaccine [4]. In 1902, Edmond Nocard $(1850$ - 1903), a French veterinarian and microbiologist isolated a virulent M. bovis strain from a cow with tuberculous mastitis. This bovine strain, "Lait Nocard," was sent to Pasteur Institute, Lille for further investigations by Calmette and Guerin. Laboratory Standardization has showed that it has Less virulence in human beings but Capable to induce the immune system. Later, Calmette and Guerin finalised to design a live vaccine from this 'Lait nocard'. They observed that addition of ox bile to the medium leads to the lowering of the virulence of the organism and this observation led them to take their long-term attempt to prepare a vaccine from live attenuated bacilli. They started their subculture work with a virulent bovine strain of tubercle bacillus in 1908. They cultured the bacilli on bile, glycerin and potato medium and then preceded to subculture at three weeks intervals. By 1919 after about 230 subcultures carried out for 11 years they succeeded to get attenuated live bacillus (later referred as BCG) which failed to produce progressive disease in animals [4].

The first human administration of BCG was carried-out on 18th July 1921 by Benjamin Weill Halle (1875-1958), through oral route. By 1924, they administrated oral BCG to 664 infants. After these reports of successful BCG vaccination, cultures of BCG were delivered for propagation in laboratories all over the world. The original $M$. bovis BCG vaccine strain was developed into several different sub strains which have been used for production of BCG vaccine. Between 1924 and 1926, 34 countries received BCG cultures from Pasteur institute (TABLE - 1) and later, many other countries were also reported to have received BCG cultures from Paris [5].

TABLE - 1: List of Countries to which BCG cultures were distributed from Pasteur Institute between 1924 and 1926 [5]

\begin{tabular}{|l|l|l|l|l|}
\hline \multicolumn{5}{|c|}{ Names of Countries } \\
\hline Algeria & Canada & Italy & Peru & Switzerland \\
\hline Argentina & Columbia & Japan & Poland & Syria \\
\hline Austria & Czechoslovakia & Lithuania & Romania & Uruguay \\
\hline Belgium & Germany & Mauritius & Russia & USA \\
\hline Bolivia & Greece & Mexico & Scotland & Venezuela \\
\hline Brazil & Holland & Norway & Spain & Yugoslavia \\
\hline Bulgaria & Hungary & Palestine & Sweden & \\
\hline
\end{tabular}




\section{Lubeck Disaster}

In 1930, a BCG campaign was scheduled in Lubeck, a northern town of Germany to vaccinate about 250 infants. BCG was supplied from Pasteur Institute, Paris and unfortunately, 73 infants were died of tuberculosis. This tragic disaster was followed by investigations which revealed the contamination of the vaccine by virulent tubercle bacilli [4]. However, this incidence shattered the confidence on BCG and lead to several field trials on the vaccine and its efficacy.

\section{Clinical trials and case-control studies}

In the mid-1930s the safety and efficacy of BCG vaccines were epidemiologically assessed by properly conducted trials. Vaccine efficacy is expressed as the per cent reduction in risk of disease in vaccinated individuals when compared to comparable non-vaccinated individuals [6]. A list of controlled trials that were begun in 1930s and the well-known trials are shown in TABLE -2 .

TABLE - 2: Clinical trials of BCG vaccine [3]

\begin{tabular}{|c|c|c|c|c|c|}
\hline S. No & Trial & Country & Year & Description & $\mathbf{R R}$ \\
\hline 1 & Saskatchewan Trial [7] & Canada & 1933 & $\begin{array}{l}\text { 609 Saskatchewan-American infants were included } \\
\text { Incidence among Vaccinated - 6/306 } \\
\text { Incidence among Control - 29/303 }\end{array}$ & 0.20 \\
\hline 2 & Aronson trial [8] & USA & 1935 & $\begin{array}{l}262 \text { American individuals were included } \\
\text { Incidence among Vaccinated - } 4 / 123 \\
\text { Incidence among Control - } 11 / 139\end{array}$ & 0.41 \\
\hline 3 & $\begin{array}{l}\text { Rosenthal-chicago trial- } \\
1[9]\end{array}$ & USA & 1937 & $\begin{array}{l}3381 \text { Chicago infants were included } \\
\text { Tice BCG was used } \\
\text { Incidence among Vaccinated - 17/1716 } \\
\text { Incidence among Control - } 65 / 1665\end{array}$ & 0.25 \\
\hline 4 & $\begin{array}{l}\text { Rosenthal-chicago trial- } \\
2[10]\end{array}$ & USA & 1941 & $\begin{array}{l}\text { 451 Chicago newborns were included } \\
\text { Incidence among Vaccinated - } 3 / 231 \\
\text { Incidence among Control - } 11 / 220\end{array}$ & 0.26 \\
\hline 5 & Muscogee trial [11] & USA & 1947 & $\begin{array}{l}\text { 4839 Muscogee school children were included } \\
\text { Tice BCG was used } \\
\text { First trial supported by WHO+USPHS } \\
\text { Incidence among Vaccinated - 5/2498 } \\
\text { Incidence among Control - } 3 / 2341\end{array}$ & 1.56 \\
\hline 6 & Puerto Rico trial [12] & USA & $\begin{array}{c}1949 \text { to } \\
1969\end{array}$ & $\begin{array}{l}77972 \text { children and adults were included } \\
\text { Study was supported by USPHS } \\
\text { Birkhaug BCG was used } \\
\text { Incidence among Vaccinated - } 186 / 50634 \\
\text { Incidence among Control - } 141 / 27338 \\
\end{array}$ & 0.71 \\
\hline 7 & $\begin{array}{l}\text { Muscogee and Russel } \\
\text { trial [13] }\end{array}$ & USA & $\begin{array}{c}1950 \text { to } \\
1970\end{array}$ & $\begin{array}{l}34567 \text { individuals with }>5 \text { years were included } \\
\text { Study was supported by USPHS } \\
\text { BCG obtained from Rosenthal was used } \\
\text { Tuberculin test and X-ray examination were carried } \\
\text { out before vaccination } \\
\text { Incidence among Vaccinated - } 27 / 16913 \\
\text { Incidence among Control - 29/17854 }\end{array}$ & 0.98 \\
\hline 8 & MRC trial [14] & UK & $\begin{array}{c}1950 \text { to } \\
1967\end{array}$ & $\begin{array}{l}26465 \text { British school children and school leavers with } \\
14-15 \text { years were included } \\
\text { Tuberculin test and X-ray examination were carried } \\
\text { out before vaccination } \\
\text { BCG Copenhagen was used } \\
\text { Incidence among Vaccinated - 62/13598 } \\
\text { Incidence among Control - 248/12867 }\end{array}$ & 0.24 \\
\hline 9 & $\begin{array}{l}\text { South India- } \\
\text { Madanapalle trial [15] }\end{array}$ & India & 1950 & $\begin{array}{l}\text { About } 21,000 \text { villagers were included and TST } \\
\text { performed with } 5 \mathrm{TU} \text { of Danish PPD } \\
\text { The non-reactors were included and divided in to } \\
\text { vaccinated and unvaccinated individuals. } \\
\text { Out of } 10877 \text { non-reactive subjects } \\
\text { Incidence among Vaccinated - } 33 / 5069 \\
\text { Incidence among Control - } 47 / 5808\end{array}$ & 0.80 \\
\hline 10 & $\begin{array}{l}\text { Chingleput major trial } \\
\text { [16] }\end{array}$ & India & 1968 & $\begin{array}{l}505 \text { TB cases among vaccinated } \\
499 \text { TB cases among unvaccinated }\end{array}$ & 1.01 \\
\hline \multicolumn{4}{|c|}{ Overall RR (95\% Confidence Interval) } & $0.49(0.34-0.70)$ & \\
\hline
\end{tabular}

Despite the nature of results of randomized controlled trials including Chingleput trial, BCG vaccination continues to be recommended by $\mathrm{WHO}$ as a part of immunization programme for infants in the majority of the countries. So, the epidemiologists and researchers decided to assess the efficacy of the vaccine retrospectively by estimating the effect of TB rates on who had BCG at birth or at campaigns. A list of ten wellknown case control studies is shown in TABLE -3 . 
Lait nocard to rBCG - over 100 years of experience with BCG Vaccine

TABLE - 3: Case Control studies of BCG vaccine [3]
\begin{tabular}{|l|c|c|c|c|c|}
\hline \multirow{2}{*}{ Study Reference } & \multicolumn{2}{|c|}{ TB cases } & \multicolumn{2}{c|}{ Controls } & \multirow{2}{*}{ Odds ratio } \\
\cline { 2 - 6 } & BCG & No BCG & BCG & No BCG & Od \\
\hline Putrali 1983 [17] & 59 & 44 & 281 & 131 & 0.63 \\
\hline Shapiro 1985 [18] & 38 & 140 & 247 & 73 & 0.84 \\
\hline Young \& Hershfield 1986 [19] & 35 & 36 & 163 & 50 & 0.39 \\
\hline Myint 1987 [20] & 162 & 149 & 977 & 559 & 0.62 \\
\hline Miceli 1988 [21] & 50 & 125 & 519 & 356 & 0.27 \\
\hline Packe \& Innes 1988 [22] & 62 & 46 & 336 & 96 & 0.36 \\
\hline Houston 1990 [23] & 65 & 78 & 148 & 103 & 0.58 \\
\hline Sirinavin 1991 [24] & 57 & 18 & 189 & 18 & 0.17 \\
\hline Rodrigues 1991 [25] & 57 & 54 & 356 & 199 & 0.51 \\
\hline Patel 1991 [26] & 57 & 82 & 140 & 156 & 0.79 \\
\hline Overall OR (95\% Confidence Interval) & \multicolumn{3}{c|}{$0.50(0.39-0.64)$} \\
\hline
\end{tabular}

\section{Variation in protection by BCG - Hypotheses}

Several different hypotheses were proposed for the failure of BCG vaccine to protect against TB in the field trials [2], [6] , [27] and are reviewed below.

\section{Previous exposure with atypical mycobacteria}

This hypothesis is oldest and still one of the most popular explanation for the failure of protective efficacy offered by the BCG vaccination. The previous sensitization and infection with environmental atypical mycobacteria provide some protection against $M$. tuberculosis and then the effect of later BCG is partially masked. Numerous species of mycobacteria are found in soil and water and many of human beings are sensitized to these bacteria and this hypothesis would appear to be plausible. The fact that atypical mycobacteria (NTM) were isolated from $8.6 \%$ of sputum specimens collected from the study area of Chingleput BCG trial lends support to this theory [28].

Animal studies have provided additional evidence that sensitization with environmental mycobacteria may have a direct antagonistic effect on BCG vaccination. Mice pre-sensitized with $M$. avium or with cocktails of $M$. avium, $M$. vaccae and $M$. scrofulaceum developed antimycobacterial responses that control the multiplication of BCG, thereby reducing its protective efficacy against TB [29]. Sensitization with M. avium or M. fortuitum before vaccination with BCG also showed a modulatory effect on the protective efficacy of BCG against experimental TB in guinea pigs [30]. These results strongly suggest that prior exposure to live environmental mycobacteria primes the host immune system against mycobacterial antigens shared with BCG and that recall of this immune response on vaccination results in accelerated clearance of BCG and hence decreased protection against TB.

\section{Differences between BCGs}

The differences in the potency, immunogenecity and dose of individual vaccine strains are also considered as the most important hypotheses for the failure of BCG vaccine. Similar vaccines showed very different efficacies in the Chingleput and British trials against tuberculosis. In Chingleput BCG trial two different vaccines of BCG the French and Danish, with a high dose $(0.1 \mathrm{mg} / 0.1 \mathrm{ml})$ and a low dose $(0.01 \mathrm{mg} / 0.1$ $\mathrm{ml}$ ) were used and showed similar protection against tuberculosis [31] [32].

\section{Differences in natural history of infection and disease}

According to this hypothesis, the variation in efficacy could be related to differences in risk of infection, differences in M. tuberculosis or to differences in pathogenesis of disease. Studies in guinea pigs have shown that the protection imparted by BCG vaccines may differ according to the exposure of strain of M. Tuberculosis [33].

\section{Variations in host genetics or nutrition}

This hypothesis depends upon gender difference and other genetic differences that are believed to play a role in the differential protection offered by BCG [27]. There is no direct evidence that the variation in the protection imparted by BCG is related to genetic factors in human populations. However large scale studies at molecular level may provide vital information.

\section{Differences in nutritional status}

As nutritional status affects the functioning of the cellular immune system, it might be expected that poor nutritional status would adversely affect the protective efficacy of BCG vaccination [27]. To support this hypothesis, large scale epidemiological studies are needed. 


\section{Methodological differences in the trials}

The mathematical and statistical differences between sample size, field methods and other sampling differences were also considered for the variable results in the protection offered by the BCG [27].

\section{Problem addressed}

Approximately 100 million children receive BCG annually throughout the world today [34]. Most of the countries follow the Universal Immunisation Programme which recommends only a single dose of BCG given at birth or at earliest contact with a health service. These BCG vaccines consistently give good protection against childhood manifestations of TB when administered before sensitization with environmental mycobacteria [35]. However, as the activity of the neonatal vaccination wanes after 10-12 years [36], the incidence of pulmonary TB increases in adolescence [37]. The mechanism underlying the gradual loss of effectiveness of BCG (neonatally vaccinated) as the individual reaches 10 to 15 years of age is poorly understood. Moreover these adolescent/young adult population are highly sensitized due to the combination of BCG vaccine, environmental mycobacteria and in some cases with latent TB infection. Unvaccinated subjects also develop natural immunity with time, through the exposure with environmental mycobacteria.

If BCG vaccination given at birth can give only short-lived immunity, the options are either to replace BCG with a vaccine that gives a longer duration of protection or to design a vaccine that can be given at a later time point to boost existing immunity and provide protection in adults who are sensitized with environmental mycobacteria and/or might have latent TB infection [38].

Several reviews have addressed the need for newer TB vaccines [39, 40, 41, 42, 43, 44, 45, 46, 47]. Yet another significant add-on problem is the different strains that involved in TB infection. Molecular epidemiological studies are needed in parallel to understand the different strains involved in TB infection and the immune response against multiple strains in $M$. tuberculosis. Different vaccine development strategies were started and are; Genetically modified-BCG vaccines, Attenuated strains of M. tuberculosis, Non-mycobacterial live vaccines, Attenuated mycobacterial species, Subunit and DNA vaccines [48]. The recent advances in the development of new vaccines against tuberculosis have entered into clinical trials.

\section{New TB vaccines in Clinical Trials}

The research communities work on tuberculosis agree that new vaccines are important to future TB elimination programs. There are 13 vaccine candidates for tuberculosis that are being in clinical trials [1]. Five vaccines are in Phase I and Eight in Phase II / III trials. They include candidates for the prevention of tuberculosis infection and candidates for prevention of TB disease in people with Latent Tuberculosis Infection.

\section{Vaccines in Phase I trials MVA85A}

MVA85A (Aerosol) was developed at the University of Oxford which is an aerosolized vaccine. The safety and immunogenicity of this vaccine has been tested in United Kingdom among 24 BCG vaccinated adults during Phase I trial. It appears to be a safe and produces a stronger CD4+ T-cell response.

\section{Ad5 Ag85A}

Ad5 Ag85A was developed by McMaster University with support from CanSino. This is an adenovirus serotype 5 vector expressing the Ag85A. The efficacy has been evaluated in 24 healthy human volunteers in Canada. It was found to be immunogenic and safe.

\section{MTBVAC}

MTBVAC was developed by the University of Zaragoza, Institut Pasteur and Biofabri, with the support of the TB Vaccine Initiative (TBVI). This vaccine is a live M. tuberculosis strain attenuated by the deletions of the phoP and fadD26 genes.

\section{ChAdOx1.85 A}

ChAdOx1.85 A was developed at the University of Oxford to boost BCG induced protection. This is a simian adenovirus expressing antigen $85 \mathrm{~A}$. It is being evaluated in a Phase I trial in BCG-vaccinated adults.

\section{TB/FLU-04 L}

TB/FLU-04 L was developed by the Research Institute for Biological Safety Problems and the Research Institute on Influenza in the Russian Federation. It is a recombinant influenza vectored vaccine candidate. It was designed as a boost vaccine for infants, adolescents and adults. A Phase I trial was carried out among BCG-vaccinated QuantiFERON-TB-Gold negative healthy adult volunteers and a Phase IIa trial is planned. 


\section{vaccines in Phase II or Phase III trials \\ VPM 1002}

VPM 1002 is a live recombinant vaccine which was jointly developed at the Max Planck Institute of Infection Biology, Germany, Vakzine Projekt Management, the Tuberculosis Vaccine Initiative and the Serum Institute of India. A Phase II trial is being carried-out in South Africa among HIV exposed and unexposed neonates.

\section{M72/AS01E}

M72/AS01E was developed by GlaxoSmithKline and is a recombinant fusion protein of the M. tuberculosis antigens $32 \mathrm{~A}$ and $39 \mathrm{~A}$. It also contains the adjuvant AS01E. A large randomized placebo-controlled Phase IIb trial, conducted among pulmonary TB and HIV-negative adults in Kenya, South Africa and Zambia.

\section{H4:IC31}

The H4:IC31was initially developed by the Statens Serum Institute (SSI) in Copenhagen, Denmark and now is being developed as a booster vaccine to BCG with Sanofi Pasteur. It contains a fusion protein of Ag85B and TB10.4, formulated with the IC31 adjuvant. It is being tested in Phase II at South Africa in a among HIVnegative adolescents at high risk of acquiring M. tuberculosis infection

\section{H56:IC31}

H56:IC31 is also developed by Statens Serum Institute (SSI) in Copenhagen, Denmark along with Aeras, a non-profit biotechnology organization works on new TB vaccines. It is an adjuvanted subunit vaccine that combines three M. tuberculosis antigens (Ag85B, ESAT-6 and Rv2660c) with Valneva's IC31 adjuvant. The Phase I trials have shown the safety and found to be immunogenic.

\section{RUTI}

RUTI is a poly-antigenic vaccine developed by Archivel Farma, Spain based on the fragmented M. tuberculosis. This is an immunotherapeutic vaccine. Phase II trial was completed in South Africa.

\section{DAR-901}

The DAR-901 was developed by Dartmouth and Aeras which is a booster vaccine with heat inactivated, wholecell non-tuberculous mycobacteria. Earlier trials shown to be effective in Phase I conducted at United States of America among BCG-primed adults with and without HIV infection.

\section{ID93 + GLA-SE}

The ID93 + GLA-SE vaccine was developed by the Infectious Disease Research Institute in collaboration with Aeras. It comprises of three M. tuberculosis immune-dominant antigens namely Rv2608, Rv3619 and Rv3620 along with one M. tuberculosis latency-associated antigen Rv1813. It also contains the adjuvant GLA-SE. A Phase I trial in BCG-vaccinated, QuantiFERONTB-Gold negative and positive healthy adults has been completed in South Africa and found to have an acceptable safety.

\section{Vaccae $^{\mathrm{TM}}$}

The Vaccae ${ }^{\mathrm{TM}}$ vaccine is a lysate vaccine developed by Anhui Zhifei Longcom Biologic Pharmacy Co Ltd, China. Phase III trial is under process in collaboration with the Guangxi Center for Disease Control and Prevention in China, to assess its efficacy and safety in people with LTBI.

\section{Conclusion}

The slow decline in global TB incidence and the continual threat of Multi Drug Resistant Tuberculosis highlight the vital need for new TB vaccines that are more effective than the Bacille-Calmette-Guérin (BCG). H. M. Dockrell [49] has already reviewed the major challenges for the research communities work on TB vaccine development. They are Global TB epidemic statistics along with Multi Drug resistance and HIV coinfection, The type of vaccine that we do need, How to identify the most promising vaccine candidates, Lack of Biosignatures that will predict the efficacy and Loss of confidence following MVA85A vaccine.

The effectiveness of these new vaccine candidates to prevent TB will be revealed over the next decade. The 4th Global Forum on TB Vaccines, organized at Shanghai, China, during April 2015, has brought together the diverse community involved in tuberculosis vaccine development have proposed the future directions for this critical research and clinical trials [50]. The current available technologies of vaccine production using molecular recombinant technology tool is well established today and this leads to the development of promising vaccine candidates. However, the potential benefits of newer TB vaccines need to be reviewed in the light of the epidemiology for their promising efficacy. 


\section{References}

[1] World Health Organization. Global Tuberculosis Report 2016 (WHO Press, Switzerland, 2016)

[2] P.E.M. Fine and L.C. Rodrigues, Modern vaccines: Mycobacterial diseases, Lancet, 335 1990, 1016-1020.

[3] G.A. Colditz, T.F. Brewer, C.S Berkey , M.E. Wilson, E. Burdick , H.V. Fineberg and F. Mosteller, Efficacy of BCG vaccine in the prevention of tuberculosis. Meta-analysis of the published literature, JAMA, 27, 1994, 698-702.

[4] A. Sakula, BCG: who were Calmette and Guerin?, Thorax, 38, 1983, 806-812.

[5] T. Oettinger, M. Jorgensen, A. Ladefoged, K. Haslov and P. Andersen, Development of the Mycobacterium bovis BCG vaccine: review of the historical and biochemical evidence for a genealogical tree, Tuberc Lung Dis, 79, 1999, 243-250.

[6] P. E.M. Fine, BCG vaccination against tuberculosis and leprosy, Brit. Med. Bull, 44, 1988, 691-703.

[7] R.G. Ferguson and A.B. Simes, BCG vaccination of Indian infants in Saskatchewan, Tubercle, 30, $1949,5-11$.

[8] J.D. Aronson, Protective vaccination against tuberculosis with special reference to BCG vaccination, Am Rev Tuberc. 58. 1948, $255-281$.

[9] S.R. Rosenthal, E. Loewinsohn, M.L. Graham, D. Liveright, G. Thorne and V. Johnson, BCG vaccination against tuberculosis in Chicago: a 20-year study statistically analyzed. Pediatrics, 28, 1961, 622-641.

[10] S.R. Rosenthal, E. Loewinsohn, M.L. Graham , D. Liveright, M.G. Thorne and V. Johnson, BCG vaccination in tuberculous households. Am Rev Respir Dis. 84, 1961, 690-704.

[11] G.W. Comstock and R.G. Webster, Tuberculosis studies in Muscogee County, Georgia. VII. A 20-year evaluation of BCG vaccination in a school population. Am Rev Respir Dis, 100, 1969, 839-845.

[12] G.W. Comstock, V.T. Livesay and S.F. Woolpert, Evaluation of BCG vaccination among Puerto Rican children. Am Jr Public Health. 4,1974, 283-291.

[13] G.W. Comstock, S.F. Woolpert and V.T. Livesay, Tuberculosis studies in muscogee County, Georgia: twenty-year evaluation of a community trial of BCG vaccination. Public Health Rep. 91, 1976, 276-280.

[14] P.D. Hart and I. Sutherland, BCG and vole bacillus vaccines in the prevention of tuberculosis in adolescence and early adult life: final report to the Medical Research Council, Br Med Jr. 2, 1977, 293-295.

[15] J.F. Moller, G.S. Acharyulu and K.K. Pillai, Observations on the protective effect of BCG vaccination in a south Indian rural population, Bull Int Union Tuberc. 48,1973, 40-52.

[16] Indian council of Medical Research, Tuberculosis prevention trial. Ind Jr Med Res. 72, Suppl. 1980, 1-74.

[17] J. Putrali, B. Sutrisna, N. Rahayoe and A.S. Gunardi, A case-control study of effectiveness of vaccination in children in Jakarta, Indonesia. Proceedings of the Eastern Regional Tuberculosis Conference of IUAT, Indonesia, 1983, 194-200.

[18] C. Shapiro, N. Cook, D. Evans, W. Willett, 1. Fajardo, D. Koch-Eser, G. Bergonzoli, O. Bolanos, R. Guerrero and C.H Hennekens, A case-control study of BCG and childhood tuberculosis among children in Cali, Colombia, Int Jr Epidemiol. 14, 1985, 441-446.

[19] T.K. Young and E.S. Hershfield, A case-control study to evaluate the effectiveness of mass neonatal BCG vaccination among Canadian Indians, Am Jr Public Health, 76, 1986, 783-786.

[20] T.T. Myint, H. Win, H.H. Aye and T.O. Kyaw-Myint, Case-control study on evaluation of BCG vaccination of newborns in Rangoon, Burma, Ann Trop Paediatr. 7, 1986, 159-166.

[21] I. Miceli, I.N. De Kantor, D. Colaiacovo, G. Peluffo, I.Cutillo, R. Gorra, R. Botta, S. Hom and H.G. Dam, Evaluation of the effectiveness of BCG vaccination using the case-control method in Buenos Aires, Argentina. Int Jr Epidemiol. 17, 1988, 629-634.

[22] G.E. Packe and J.A. Innes, Protective effect of BCG vaccination in infant Asians: a case-control study. Arch Dis Child. 63, 1988, 277-281.

[23] S. Houston, A. Fanning, C.L. Soskoine and N. Fraser, The effectiveness of bacillus Calmette-Guerin (BCG) vaccination against tuberculosis. Am Jr Epidemiol. 131, 1990, 340-349.

[24] S. Sirinavin, T. Chotpitayasunondh, S. Suwanjutha, P. Sunakorn and T. Chantarojanasiri, Protective efficacy of neonatal bacillus Calmette-Guerin vaccination against tuberculosis. Pediatr Infect Dis Jr. 10, 1991, 359-365.

[25] L.C. Rodrigues, O.N. Gill, P.G. Smith, BCG vaccination in the first year of life protects children of Indian subcontinent ethnic origin against tuberculosis in England. Jr Epidemiol Commun Health. 45, 1991,78-80.

[26] A. Patel, F. Schofield, V. Siskind, E. Abrahams and J. Parker, Case-control evaluation of a school-age BCG vaccination programme in subtropical Australia. WHO Bull. 69, 1991, 425-433.

[27] H. L. Rieder, BCG vaccination, in P.D.O. Davies (Ed.), Clinical tuberculosis, 3 (London: Hodder \& Stoughton Ltd 2008) 337-353

[28] C.N. Paramasivan, D. Govindan, R. Prabhakar, P.R. Somasundaram, S. Subbammal and S.P. Tripathy, Species level identification of non-tuberculous mycobacteria from South Indian BCG trial area during 1981, Tubercle, 66, 1985, 9-15.

[29] L. Brandt, J.F. Cunha, A.W. Olsen, B. Chilima, P. Hirsch, R. Appelberg and P. Andersen, Failure of the Mycobacterium bovis BCG vaccine: some species of environmental mycobacteria block multiplication of BCG and induction of protective immunity to tuberculosis, Infect. Immun, 70, 2002, 672-678.

[30] T. Kamala, C.N. Paramasivan, D. Herbert, P. Venkatesan and R. Prabhakar, Immune response and modulation of immune response induced in the guinea-pigs by Mycobacterium avium complex (MAC) \& M. fortuitum complex isolates from different sources in the south Indian BCG trial area, Ind Jr Med Res, 103, 1996, 201-211.

[31] P.D. Hart and I. Sutherland, BCG and vole bacillus vaccines in the prevention of tuberculosis in adolescence and early adult life: final report to the Medical Research Council, Br Med Jr, 2, 1977, 293-295.

[32] Indian council of Medical Research,. Tuberculosis prevention trial, Ind Jr Med Res, 72, 1980, Suppl. 1-74.

[33] J.A. Hank, J.K. Chan, M.L. Edwards, D. Muller and D.W. Smith, Influence of the virulence of Mycobacterium tuberculosis on protection induced by bacille Calmette-Guérin in guinea pigs, J Infect Dis, 143, 1981, 734-738.

[34] P.E.M. Fine, BCG vaccines and Vaccination in L.B. Reichman and E.S. Hershfield (Ed), Tuberculosis. A comprehensive international approach, (New York: Marcel Dekker; 2000) 503-22.

[35] L.C. Rodrigues, V.K. Diwan and J.G. Wheeler, Protective effect of BCG against tuberculous meningitis and miliary tuberculosis: A meta-analysis, Int Jr Epi, 22, 1993, 1154-1158.

[36] J.A.C. Sterne, L.C. Rodrigues and I.N. Guedes, Does the efficacy of BCG decline with time since vaccination?, Int Jr Tub Lung Dis, 2, 1998, 200-207.

[37] Revised National Tuberculosis Control Programme. 2009. Central TB Division. Ministry of Health and Family Welfare, Government of India.

[38] T. M. Doherty and P. Andersen, Vaccines for tuberculosis: Novel concepts and recent progress, Clin Micro Rev, 18, 2005, 687702.

[39] A.J. Crowle, Immunization against tuberculosis: What kind of vaccine?, Infect Immun, 56, 1988, 2769-2773.

[40] S.H.E. Kaufmann, Is the development of a new tuberculosis vaccine possible?, Nat me, 6, 2000, 955-960. 
[41] E.M. Agger and P. Andersen, A novel TB vaccine; towards a strategy based on our understanding of BCG failure, Vaccine, 21, 2002, 7-14.

[42] M.C. Arreola and Y. L. Vidal, A second generation anti TB vaccine is long overdue. Annals Clin Micro Antimicro, 3, 2004, 1-10.

[43] N.M. Nor and M. Musa, Approaches towards the development of a vaccine against tuberculosis: recombinant BCG and DNA vaccine, Tuberculosis, 84, 2004, 102-109.

[44] C. Martin, The dream of a vaccine against tuberculosis; new vaccines improving or replacing BCG?, Eur Resp Jr, 26, 2005, 162167.

[45] J. Dietrich, C. V. Lundberg and P. Andersen, TB vaccine strategies - What is needed to solve a complex problem?, Tuberculosis, 86, 2006, 163-168.

[46] P. Andersen, Tuberculosis vaccines - an update, Nature Reviews, 5, 2007, 484-487.

[47] E. Ziv, C.L. Daley and S. Blower, Potential public health impact of new tuberculosis vaccines, Emerg Infect Dis, 10, 2004, 15291535 .

[48] D.N. McMurray, Recent advances in improved tuberculosis vaccines. Ind Jr Ped, 67, 2000, S58-S62.

[49] H. M. Dockrell, Towards new TB vaccines: What are the challenges? Pathogens and Disease, 74, $2016,1-7$.

[50] A.M. Ginsberg, M. Ruhwald, H. Mearns, and H. McShane, TB vaccines in clinical development, Tuberculosis, 99, 2016, S16-S20.

IOSR Journal of Biotechnology and Biochemistry (IOSR-JBB) is UGC approved Journal with Sl. No. 4033, Journal no. 44202. 